\title{
LA RED DE FAMILIARES CONTRA LA TORTURA Y OTRAS VIOLENCIAS ESTATALES (CPM): SANGRE Y REENCANTAMIENTO DEL ACTIVISMO.
}

THE FAMILY NETWORK AGAINST TORTURE AND OTHER STATE VIO-

LENCE (CPM): BLOOD AND REINCARNATION OF ACTIVISM.

LE RESEAU FAMILIAL CONTRE LA TORTURE ET LES AUTRES VIOLENCES COMMISES PAR LES ETATS (CPM): SANG SUR LE SANG ET REINCARNATION DE L'ACTIVISME.

RESUMEN: En febrero de 2017 se constituye la Red de Familiares contra la Tortura y otras Violencias Estatales, que reúne a un amplio y diverso conjunto de agrupaciones bajo la órbita de la Comisión Provincial por la Memoria (Buenos Aires, Argentina). En este trabajo problematizamos cómo se resignifican distintas figuras y sentidos establecidos del activismo de las víctimas en el campo de los derechos humanos a partir de repertorios, símbolos y experiencias provenientes del mundo religioso (católico, en este caso) que ponen en tensión la noción misma de "familia", de "comunidad de sangre" y de "militancia". Estas tensiones y nuevos sentidos emergentes ponen en evidencia un proceso de reencantamiento del activismo de los derechos humanos, construido socialmente como un espacio secularizado.

Palabras clave: activismo; violencia estatal; familiares; sangre; religión.

ABSTRACT: In February 2017, the Family Network against

\footnotetext{
* Licenciado en Ciencia Política; Doctorando en Ciencias Sociales y Humanidades por la Universidad Nacional de Quilmes (UNQ); Becario del Centro de Estudios y Investigaciones Laborales (CEIL) del Consejo Nacional de Investigaciones Científicas y Técnicas (CONICET), Buenos Aires, Argentina; e-mail: matiasjavieraparicio@gmail.com
} 
La red de familiares contra la tortura y otras violencias estatales (CPM): sangre y reencantamiento del activismo.

Torture and other State Violence was constituted, which brings together a wide and diverse group of groups under the orbit of the Provincial Commission for Memory (Buenos Aires, Argentina). In this work we problematize how different figures and established meanings of the activism of victims in the field of human rights are resigned from repertoires, symbols and experiences from the religious world (Catholic, in this case) that stress the notion itself of "family", "community of blood" and "militancy". These tensions and emerging new senses highlight a process of reincarnation of human rights activism, socially constructed as a secularized space.

Keywords: activism; state violence; relatives; blood; religion.

RÉSUMÉ: En février 2017, le Réseau familial contre la torture et les autres actes de violence perpétrés par l'État a été constitué. Ce réseau rassemble un groupe de groupes nombreux et variés sous l'orbite de la Commission provinciale de la mémoire (Buenos Aires, Argentine). Dans ce travail, nous problématisons la façon dont différentes figures et significations établies de l'activisme des victimes dans le domaine des droits de l'homme sont résignées des répertoires, symboles et expériences du monde religieux (catholique en l'occurrence) qui soulignent la notion elle-même. "famille", "communauté de sang" et "militantisme". Ces tensions et ces nouveaux sens émergents illustrent un processus de réincarnation de l'activisme des droits de l'homme, construit socialement comme un espace sécularisé.

Mots-clés: activisme; violence de l'État; membres de la famille; sang; religion.

RESUMO: Em fevereiro de 2017, foi constituida a Rede Familiar contra a Tortura e outras Violências de Estado, que reúne um amplo e diversificado grupo de grupos sob a órbita da Comissão Provincial de Memória (Buenos Aires, Argentina). Neste trabalho, problematizamos como diferentes figuras e significados estabelecidos do ativismo das vítimas no campo dos direitos humanos se resignam de repertórios, símbolos e experiências do mundo religioso (católico, neste caso) que enfatizam a própria noção de "família", "comunidade de sangue" e "militância". Essas tensões e novos sentidos emergentes destacam um processo de reencarnação do ativismo dos direitos humanos, socialmente construído como um espaço secularizado.

Palavras-chave: ativismo; violência estatal; membros da família; sangue; religião. 


\section{INTRODUCCIÓN}

En este trabajo nos proponemos indagar las relaciones entre el mundo religioso y el activismo de familiares de víctimas de las violencias estatales a partir del papel que juega el repertorio católico al interior de la Comisión Provincial por la Memoria de la Provincia de Buenos Aires (CPM). En particular, analizaremos la Red de Familiares contra la Tortura y otras Violencias Estatales (RED) y pondremos el foco en una de sus organizaciones: Lázaro levántate y anda (LLyA), proveniente del partido de La Matanza.

La Comisión Provincial por la Memoria es un organismo público de extrapoderes de con funcionamiento autónomo y autárquico, que desarrolla políticas de memoria sobre el pasado autoritario argentino (Raggio, 2004 y 2006). Fue creada por el parlamento de la provincia en 1999 y funciona bajo esa órbita desde el año 2000. Está integrada por referentes de organismos de derechos humanos, del sindicalismo, la justicia, la legislatura, universidades y representantes religiosos de diversos espacios (Raggio, 2006; Lorenz, 2007) que componen tanto la comisión de notables, como el equipo técnico que realiza las tareas cotidianas (Cueto Rúa, 2018).

La denominación de la Red de Familiares contra la Tortura y otras Violencias Estatales explícita desde su nombre su propósito de ser un espacio de encuentro y organización de familiares que luchan contra las violencias estatales. Aunque fue creada formalmente en 2017, sus antecedentes se remontan a 2004.

A su vez, la organización Lázaro levántate y anda adquirió esta denominación recién en el 2007, aunque sus orígenes se retrotraen a los 2000. Sus áreas de actuación van desde casos asociados a la violencia de género hasta aquellos referidos a la violencia institucional, pasando por un amplio abanico de intervenciones asociadas a las dimensiones que los mismos actores identifican como de jóvenes y familia.

Metodológicamente este trabajo - parte de una investigación más amplia- ${ }^{1}$ cuenta con tres elementos centrales. El primero de

1 El presente texto se encuentra en diálogo con el trabajo doctoral en curso "Activismo religioso católico, violencia institucional y acceso a la justicia en el Conurbano sur del GBA (2014-2021)". Esta investigación se aboca a los dispositivos estatales de acceso a la justicia, particularmente en el caso de las Agencias Territoriales de Acceso a la Justicia (ATAJO) de la Dirección General de Acceso a la Justicia del Ministerio Público Fiscal de la Procuración General de la Nación. Se analiza 
La red de familiares contra la tortura y otras violencias estatales (CPM):

sangre y reencantamiento del activismo.

ellos, la documentación producida desde la Comisión Provincial por la Memoria y la Red de Familiares contra la Tortura y otras Violencias Estatales (folletos, volantes, gacetillas de prensa, informes, etc.) a los cuales pudimos acceder por su carácter público (disponibles en sus páginas de internet y redes sociales) o por haber sido facilitado por los actores entrevistados. El segundo, refiere a la realización de entrevistas semiestructuradas. Para las mismas se contactó a miembros de la RED mediante sus redes sociales; una vez logrado el acceso al campo se paso a aplicar el método de bola de nieve (Izquierdo, 2015). Tras un primer contacto con referentes de la agrupación $\mathrm{Fa}$ miliares de Detenidos y Liberados La Gramsci (FADELI), pudimos mantener entrevistas con referentes de la Cooperativa Esperanza y particularmente con Blanca Careaga, referente de Lázaro levántate $y$ anda. 2 El tercer elemento consiste en la realización de observaciones participantes de actividades públicas organizadas por la Comisión Provincial por la Memoria. En particular, aquí presentaremos el homenaje realizado en Punta Indio el 14 de febrero de 2018 con motivo del sexto aniversario de la muerte de Sebastián Nicora. ${ }^{3}$

El trabajo cuenta con una primera sección que presenta brevemente las políticas públicas estatales que se generaron en torno a la experiencia del terrorismo de Estado. En este marco se identifica la creación de la Comisión Provincial por la Memoria y la diversificación de sus aéreas de competencia. Luego ahondaremos en la creación, cambio de nominación y caracterización de la Red de Familiares contra la Tortura y otras Violencias Estatales, haciendo foco en tres dimensiones: las organizaciones de familiares, la tematización de la sangre y del dolor. En tercer lugar, trabajaremos con

\footnotetext{
allí la articulación entre referentes religiosos y funcionarios estatales para garantizar el derecho al acceso a la justicia y afrontar las violencias que se hacen presentes en los territorios donde funciona el dispositivo. En ese marco, hemos realizado durante seis meses observaciones participantes semanales en dichos dispositivos, hemos realizado entrevistas a distintos referentes y concurrido a múltiples actividades, actos, homenajes, ligados a la temática. Esta indagación se encuentra en estrecho diálogo con el activismo contra las violaciones a derechos humanos en democracia que abordamos en el marco de la CPM. Esta relación emergente del campo impulsa estas líneas.

2 Todas las entrevistas son de elaboración propia; los actores permitieron el uso de sus nombres, sin embargo, hemos decidido explicitar solo el nombre de Careaga por la relevancia del patronímico para el análisis.

3 Sebastián Nicora, de 16 años, fue encontrado muerto en la playa de El Pericón, Punta Indio (Buenos Aires). A diferencia de lo reportado en el primer informe policial, no murió por un golpe sino por una bala en su cabeza. Los homenajes en su memoria se realizan en el lugar donde se encontró su cuerpo. Allí se erigió un mástil con una placa. Cuando falleció su madre se añadió allí otra placa en su honor.
} 
la organización Lázaro levántate y anda para analizar la emergencia de una modalidad de activismo humanitario que enlaza los derechos humanos con la creencia religiosa en los milagros. Como veremos, el componente religioso, particularmente a través del repertorio e imaginario católico se hace presente en las distintas secciones analizadas, poniendo de manifiesto la articulación entre el activismo en derechos humanos (usualmente asociado a un espacio secularizado) y el mundo religioso. Esta influencia de lo religioso acaba por dar cuenta de un reencantamiento del activismo humanitario.

\section{TERRORISMO DE ESTADO Y POLÍTICAS PÚBLICAS: UNA BREVE RECONSTRUCCIÓN}

El discurso moderno de los derechos humanos se originó estableciendo un distanciamiento de discursividades religiosas para su conceptualización (Agudelo Ramírez, 2011). Aunque en la Argentina la construcción del campo de los derechos humanos se valió en sus inicios de infraestructuras y recursos del mundo religioso, estos nexos se mantuvieron en tensión por la denuncia de la complicidad de las autoridades eclesiásticas con la dictadura militar (1976-1983) y la decepción que esto generó, incluso dentro de las propias filas del catolicismo (Catoggio, 2016b). Esto no impidió que diversas figuras provenientes del mundo católico cobrarán un papel protagónico e incluso de prestigio entre los expertos en el campo. Fue el caso, por ejemplo de Augusto Conte Mac Donell ${ }^{4}$ en la política nacional, conocido como el "diputado de los derechos humanos" por su banca por la Democracia Cristiana en los años ochenta, o del obispo Jaime Francisco de Nevares que conformó la Comisión Nacional sobre la Desaparición de Personas (CONADEP) en la misma época, entre otros.

La figura de Nevares es particularmente útil en este punto ya que fue un miembro fundador de ONGs de inspiración cristiana como la Asamblea Permanente por los Derechos Humanos (APDH) creada en 1975 y el Movimiento Ecuménico por los Derechos Huma-

4 Augusto Conte (1927-1992) fue un referente del Partido Demócrata Cristiano que accedió a su banca en las elecciones presidenciales y legislativas de 1983. Fue además uno de los miembros fundadores del Centro de Estudios Legales y Sociales (CELS), un organismo pionero en la presentación judicial de causas para la defensa de detenidos-desaparecidos por razones políticas. 
La red de familiares contra la tortura y otras violencias estatales (CPM):

sangre y reencantamiento del activismo.

nos (MEDH) surgido en 1976. Con la misma inspiración cristiana, se creó en 1974 la coordinación latinoamericana del Servicio de Paz y Justicia (SERPAJ) (Catoggio, 2015).

En diálogo con estos organismos, entre tantos otros, familiares de las víctimas del terrorismo de Estado impulsaron sus demandas de justicia. Aunque, la demanda de justicia por parte de actores que se presentaban en la arena pública como familiares data de principios de del siglo $\mathrm{XX}$, fue durante la última dictadura militar que los familiares de víctimas del terrorismo de Estado ganaron protagonismo como un actor público central en materia de derechos humanos (Pereyra Iraola y Zenobi, 2016). ${ }^{5} \mathrm{Al}$ interior del movimiento de derechos humanos la relación directa, o lo que es lo mismo, los vínculos de sangre con las víctimas, representa al conjunto de agrupaciones que históricamente han ganado mayor legitimidad pública (Vecchioli, 2005; Cueto Rúa, 2010).

La finalización de la dictadura estuvo marcada por la conformación a escala global de la justicia transicional que contó con los sectores de clase media como principales impulsores de organizaciones humanitarias (Crenzel, 2013). En ese contexto tuvo lugar la creación CONADEP ${ }^{6}$ la cual integró en su seno a diversos actores del mundo religioso, privilegiando en este caso la legitimidad de los actores por sobre su saber técnico acerca de un campo que aún estaba en ciernes. Se inició, a su vez, un proceso de judicialización inédito en la región con el Juicio a las tres primeras Juntas Militares realizado en 1985. Sin embargo, este proceso fue tempranamente interrumpido de la mano de los presidentes Raúl Alfonsín (19831989) y Carlos Saúl Menem (1989-1999) por las leyes de Punto Final de 1986 (que estipulaba un plazo de 30 días para recibir denuncias

\footnotetext{
5 En la década de los noventa los organismos de derechos humanos comenzaron a interactuar en la arena pública con organizaciones de familiares que concebían su lucha contra la impunidad y la violencia policial como un legado de la lucha de las organizaciones generadas en torno a la denuncia de las violaciones de derechos humanos de la dictadura (Pereyra Iraola y Zenobi, 2016). 6 Finalizada la dictadura, en el marco de un proceso de transición democrática, la creación de la CONADEP, y el informe que generó (Nunca Más), fueron las primeras acciones basadas en el principio de verdad que se implementaron en el país. En este contexto de justicia transicional, la CONADEP constituyó una comisión oficial de investigación creada en 1983 por el entonces presidente de la Nación, el radical Raúl Alfonsín, mediante el decreto presidencial 187/83. Conformada por un conjunto de personalidades destacadas (ya sea por sus cualidades humanitarias o profesionales), su objetivo fue el de develar el destino de los detenidos-desaparecidos e investigar las violaciones a derechos humanos realizadas durante la última dictadura (Arnoso Martínez, Bombelli, Muratori, Mele, y Zubieta, 2013).
} 
contra los militares por violaciones de derechos humanos, la ley de Obediencia Debida de 1987 (que absolvía a los rangos intermedios e inferiores), y los indultos de 1989 y 1990 que conformaron un paquete de medidas conocidas como las "leyes del perdón". Este conjunto de medidas abrió una nueva etapa en la que los crímenes de la dictadura parecían ser casi un asunto cerrado.

A mediados de la década de los noventa, cambió nuevamente el escenario de la mano de organizaciones de familiares de víctimas del terrorismo estatal quienes al reclamo de justicia sumaron la demanda de memoria. En este contexto surgió la CPM, una institución que, si bien da cuenta de una articulación entre el mundo humanitario y el aparato estatal, no implica una experiencia novedosa particularmente: la Comisión Nacional por el Derecho a la Identidad (CONADI), creada en 1992, y el emplazamiento del monumento a las Víctimas del Terrorismo de Estado, a finales de los noventa, dan cuenta de la preexistencia de este tipo de articulaciones (Cueto Rúa, 2019). En este sentido, la creación de la CPM capitaliza estas experiencias previas y toma como modelo de conformación a la CONADEP al convocar a la conformación de una comisión de notables para que acompañe y respalde a su equipo técnico.

La década siguiente trajo consigo un cambio de escala en las políticas estatales de derechos humanos. Durante los gobiernos kirchneristas (2003-2015), ${ }^{7}$ aunque particularmente el primero de ellos encabezado por Néstor Kirchner (2003-2007), se registraron múltiples políticas públicas estatales destinadas a consagrar la memoria sobre el terrorismo de Estado los derechos humanos se configuraron como una cuestión central en la vida del Estado (Gugliemucci, 2013).

Si bien esta gestión gubernamental no estuvo exenta de tensiones (pensemos por ejemplo en las condenas al Estado por parte de la Comisión Interamericana de Derechos Humanos -CIDH- por penas de prisión perpetua a sujetos que cometieron los delitos cuando eran menores de $\operatorname{edad}^{8} \mathrm{o}$ el paquete de leyes de mano dura conocido

\footnotetext{
7 Néstor Kirchner y Cristina Fernández de Kirchner mantuvieron la presidencia de Argentina durante tres periodos consecutivos, dichos mandatos son comúnmente conocidos como gobiernos kirchneristas.

8 El fallo remite a los casos de César Alberto Mendoza, Claudio David Núñez, Lucas Matías Mendoza, Saúl Roldán Cajal y Ricardo David Videla Fernández.
} 
La red de familiares contra la tortura y otras violencias estatales (CPM):

sangre y reencantamiento del activismo.

como Leyes Blumberg9), la anulación de las "leyes del perdón” y la reanudación de las causas judiciales por crímenes de lesa humanidad efectuados durante la última dictadura militar fueron un hecho icónico en la historia reciente argentina. En este nuevo escenario, la dimensión religiosa ocupó un lugar no menor; la recuperación y reconocimiento de la memoria de los mártires católicos dio cuenta de un acercamiento estatal a espacios de activismo proveniente del mundo religioso para abordar la temática de los derechos humanos. ${ }^{10}$ De esta manera, los derechos humanos, los actores religiosos y su reportorio simbólico, como la figura del mártir, volvían a ocupar un espacio estratégico en la agenda.

Con la llegada de Mauricio Macri a la presidencia en 2015, los derechos humanos continuaron siendo una cuestión central, sin embargo, esta centralidad se presentó como la contracara de los lineamientos kirchneristas. El recambio vino de la mano de una lectura asociada al "abuso" de los derechos humanos y la necesidad de "deskirchnerizar" a los mismos, pasando de un contenido centrado en la experiencia de la última dictadura hacia uno asociado al discurso internacional de derechos humanos (Barros y Morales, 2016).

Este recorrido nos presenta un escenario actual tenso en lo que respecta a la política de derechos humanos y al papel de las organizaciones humanitarias que forma parte del sustrato interpretativo de este trabajo. En este marco, en el próximo apartado abordaremos el rol que jugó el catolicismo como un elemento más - poco considerado- en la conformación y desarrollo de la CPM y en su diversificación de áreas de competencia.

9 En 2004, tras el secuestro y asesinato del joven de 17 años de clase media-alta Axel Blumberg, su padre, Juan Carlos, encabezó un reclamo que se tradujo en el paquete de las "leyes Blumberg" (elevación de penas mínimas y máximas para la portación de armas y para los robos cometidos con ellas; aumento en los castigos de los secuestros extorsivos seguidos de muerte y para delitos sexuales; limitaciones a la libertad condicional, etc.).

10 Durante el primer gobierno kirchnerista se mantuvo una relación prescíndete y distante con el poder episcopal pero activa en espacios de memoria de inserción popular asociadas a la defensa de los derechos humanos y la memoria de los mártires del catolicismo. Los monumentos erigidos, la participación de referentes estatales en conmemoraciones por la Masacre de los palotinos o la participación de Cristina Fernández de Kirchner en los homenajes a Carlos Mugica (2004, 2010 y 2014) permiten apreciar el acercamiento estatal a estos espacios de memoria. Las vinculaciones estatales con el universo religioso y el de sus mártires impregnaron también al discurso presidencial, lo cual se evidenció en un doble proceso de rememoración (religiosa de los desaparecidos y política de los mártires) en los homenajes (Catoggio, 2013; Catoggio 2016a). 


\section{LA COMISIÓN PROVINCIAL POR LA MEMORIA}

\subsection{La trama religiosa de la CPM: legitimación y capital militante}

En el segundo apartado comenzamos a rastrear la presencia de referentes e imaginarios religiosos en el campo de los derechos humanos. Este periodo constitutivo del campo daba cuenta de la presencia de figuras emblemáticas del mundo religioso quienes dotaban de legitimidad a las nuevas organizaciones de derechos humanos. En el caso de la CPM se da un caso análogo. Si ajustamos la mirada sobre sus miembros notables, podremos notar que, independientemente de las eventuales modificaciones que tuvieron aquí lugar a lo largo de su historia (Cueto Rúa, 2018), la CPM contó desde el comienzo entre sus integrantes a actores religiosos de diversos espacios (Raggio, 2006; Lorenz, 2007). Su búsqueda de legitimidad la convirtió en una comisión que desde su conformación contó con un perfil plural, ecuménico y multisectorial, basado en la idea de que la "gestión de la política pública de memoria necesita de cierto consenso de amplios sectores":

"La CPM (...) [reunió a miembros notables como n] Estela de Carlotto, presidenta de Abuelas de Plaza de Mayo; Adolfo Pérez Esquivel, premio Nobel de la Paz 1980 y un referente central del movimiento de derechos humanos; Laura Conte, madre de Plaza de Mayo-Línea Fundadora y vicepresidenta del Centro de Estudios Legales y Sociales (CELS); Aldo Etchegoyen, pastor de la Iglesia Metodista y también referente de la Asamblea Permanente por los Derechos Humanos y (...) miembros del sindicalismo (...), de la Justicia (...); de la Universidad Nacional de la Plata y una representación ecuménica, de diferentes credos. Está Daniel Goldman, de la comunidad judía de Buenos Aires; Aldo Etchegoyen; la monja Martha Pelloni, una reconocida luchadora por los derechos humanos." (Lenci y Raggio, 2011, p.2).

Además de las ligazones explícitas al mundo religioso que hacen Lenci y Raggio, figuras como la de Adolfo Pérez Esquivel están públicamente asociadas al mundo cristiano. También Laura Conte (es- 
La red de familiares contra la tortura y otras violencias estatales (CPM): sangre y reencantamiento del activismo.

posa de Augusto Conte Mac Donnell), quien como ya dijimos, fuera diputado por la Democracia Cristiana, provienen del mundo católico.

Si bien inicialmente, en lo que respecta a los referentes religiosos, coexistían actores de diversos espacios y confesiones, actualmente se destacan los actores católicos gracias a la incorporación del sacerdote José "Pepe" Di Paola, referente del equipo de curas villeros, y del obispo emérito de Viedma, Miguel Hesayne, reconocido por su denuncia pública de las violaciones a los derechos humanos durante la última dictadura. A este ámbito de socialización religiosa, siguiendo a nuestros entrevistados, también pertenece el referente Roberto Cipriano García, quien además de haber estado al frente del Comité contra la Tortura (CCT) de la CPM entre 2005 y 2013 y ser desde 2015 el secretario ejecutivo de la Comisión, se desempeñó como coordinador del área de violencia en contextos de encierro de la Procuraduría de Violencia Institucional (PROCUVIN) del Ministerio Público Fiscal de la Nación.

Sus notables contaron y cuentan entonces con trayectorias y modos de comprender su militancia que los vinculaban a espacios cristianos, pero ellos no fueron los únicos. El trabajo de Cueto Rúa (2018) nos permite observar la existencia de diversas experiencias de militancia asociada a espacios cristianos dentro del equipo técnico de la CPM. Los casos de Ana Cacopardo, Sandra Raggio y Fabián Salvioli pueden ilustrar este punto.

Cacopardo, una de las figuras claves para la conformación del equipo técnico de la CPM, se reconoce como militante del SERPAJ a fines de los ochenta. Desde este espacio y experiencia se puso en contacto y convocó a Raggio. Sandra, independientemente de haber transitado por el SERPAJ, comenzó su militancia brindando apoyo escolar en la Iglesia Metodista de La Plata. Salvioli por otra parte, si bien estuvo poco tiempo en el equipo técnico, presenta un perfil que conjuga su saber experto, en cuanto abogado especializado en Derechos Humanos y Derecho Internacional, con el hecho de haber sido parte del Equipo Interdisciplinario de Educación Formal del MEDH.

De este modo podemos ver como desde sus inicios la CPM tuvo entre sus integrantes tanto a actores del mundo religioso como a referentes del campo de los derechos humanos ligados públicamente a ese ámbito. 


\subsection{Estructura y diversificación de funciones}

La CPM está compuesta por cuatro grandes áreas. La primera es el Área de Educación, Investigación y Archivo. Este espacio unifica lo que otrora fueron dos áreas: la del Archivo y Documentación (dedicada desde el año 2000 a la conservación, preservación y gestión del fondo documental del ex Departamento de Inteligencia de la Policía Bonaerense) y el Área de Investigación y Enseñanza (en cuyo marco se desarrolló originalmente el programa Jóvenes y Memoria, creado en 2001).

Una segunda área es la de Comunicación y Cultura, dedicada a publicaciones, como la revista Puentes, y a organizar espacios de debate democrático. En tercer lugar, desde Justicia y Seguridad Democrática, la Comisión interviene en materia de seguridad pública y justicia con una perspectiva de derechos humanos.

En cuarto lugar se encuentra el Comité Contra la Tortura (CCT). Creado en 2002, fue el primer programa de la CPM destinado a abordar violaciones de derechos humanos desarrolladas en el contexto democrático. Desde su creación se encarga de casos de abuso policial y de la detección de violaciones de derechos en los lugares de detención de la Provincia de Buenos Aires (entiéndase cárceles, comisarías e institutos de menores) (Larralde Armas, 2014). En 2003 se inauguró el registro de casos judiciales de tortura que hizo posible, en 2004, la presentación del informe "El sistema de la crueldad", ${ }_{11}$ el primero de una serie de informes anuales inscriptos, por su sola denominación, en una retórica no solo de los abusos y del "dolor" sino de "lo inhumano". El CCT es, como veremos el antecedente directo de la conformación de la RED que nos ocupa. Su surgimiento se comprende en el marco de crecimiento de la CPM. Es decir, nacida en el marco de políticas estatales de memoria y enfocada en la violencia de la última dictadura, ha transitado un camino por medio del cual sus áreas de competencia se diversificaron. La intervención en casos actuales de violaciones de derechos humanos significó la articulación con una serie de actores y grupos novedosos para la Comisión. En el marco de la CCT, la creación de la RED de

11 Entre los objetivos del informe de 2006 figura "trabajar con los familiares de las víctimas de los lugares de detención" (CPM, 2006, p.23). Esta es la primera edición en la que se reconoce y agradece el aporte de familiares y organizaciones de familiares de víctimas de violencia institucional. 
La red de familiares contra la tortura y otras violencias estatales (CPM):

sangre y reencantamiento del activismo.

organizaciones de Familiares Víctimas de la Violencia Institucional en febrero de 2017, más tarde denominada Red de Familiares contra la Tortura y otras Violencias Estatales (RED), ${ }^{12}$ representa un hito en estos términos. El informe, antes referido, y los que siguieron año a año:

"permitieron visibilizar la sistematicidad, estructuralidad y multidimensionalidad de la tortura en la provincia. (...) Esta iniciativa implicó la presencia regular y periódica en los espacios de detención (...), la recepción y gestión inmediata de las demandas o denuncias de las víctimas de violaciones a sus derechos y el seguimiento estratégico de los casos atendidos. (...) Esta tarea de control generó un vínculo de confianza con los detenidos y sus familias, actores con los que la institución comenzó a trabajar con el objetivo de fortalecer sus capacidades de organización colectiva e intervención. De este trabajo surgió la creación de la Red de Familiares Víctimas de Violencia Institucional que cambió luego su nombre por el de Red de Familiares Contra la Tortura y otras Violencias Estatales (Raggio y Cipriano García, 2019, p.124. Resaltado propio).

En el marco del estudio de las emociones, el dolor y sus distintas formas de jerarquización así como su conceptualización en cuanto valor y fuente de legitimidad para el accionar de familiares en causas de derechos humanos ha sido trabajado en profundidad (Pereyra Iraola y Zenobi, 2016; Cueto Rúa 2019). Esta cuestión ha sido abordada tanto para comprender los activismos asociados a la violencia política como en los referidos a la violencia institucional. La principal diferencia radica en que las violaciones a derechos humanos que acontecen durante una dictadura remiten a un escenario de suspensión de las garantías constitucionales, mientras que en el caso de la violencia institucional y estatal, las violaciones rompen con la legalidad vigente.

12 En 2017 el conjunto de organizaciones de familiares adopta la sigla RED. En boletines de la CPM y en los relatos de los entrevistados se mantuvo la sigla sin alteraciones, es por ello que implementaremos la sigla en cuestión de manera indiscriminada para referirnos a estas agrupaciones, tal y como hacen los actores. 


\section{VÍCTIMAS Y FAMILIARES: DE LA VIOLENCIA INS- TITUCIONAL A LA "RED DE FAMILIARES CONTRA LA TORTURA Y OTRAS VIOLENCIAS ESTATALES (RED)”}

Así como indicamos para la CPM una serie de experiencias previas que daban cuenta de una articulación entre el mundo humanitario y el aparato estatal, a la hora de hablar de organizaciones de familiares, en este caso nucleados contra las violencias estatales, podemos poner en práctica un ejercicio similar.

Desde el caso Sivak en adelante, ${ }^{13}$ las víctimas y muertes conmocionantes que marcaron la historia reciente argentina fueron dando cuenta de un período de transición, que tenía por trasfondo la experiencia dictatorial (Gayol y Kessler, 2018), pero que daba lugar a un conjunto nuevo de estudios sobre violencias. El caso de Ingeniero Budge ${ }^{14}$ por ejemplo, fue un punto de inflexión y un caso fundacional que promovió trabajos sobre violencia policial (Cerruti, 2015; Pita, 1997, 2005 y 2010).

Siguiendo a Pita (2004), las muertes por brutalidad policial conllevaron a que, desde mediados de los ochenta apareciera en la arena pública una demanda de justicia centrada en los casos de violencia institucional, fundamentalmente policial. Este nuevo conjunto de demandas implicó la conformación de novedosas organizaciones de familiares de víctimas, como el establecimiento de comisiones de familiares al interior de organizaciones de derechos humanos asociados a los reclamos "históricos" articulados a partir de la dictadura.

El señalamiento de una continuidad entre las prácticas de brutalidad policial con metodologías represivas de la última dictadura, así como de prácticas de menor intensidad represiva, llevó a organizaciones creadas a partir de las violaciones contra los derechos humanos de la dictadura, como el CELS (1979), a erigir espacios de trabajo centrados en las violaciones a derechos en democracia.

13 Osvaldo Sivak fue un empresario a quien secuestraron en 1979 y 1985 . Tras su segundo secuestro no lo liberaron, encontrándose en 1987 su cuerpo sin vida. Representa un caso testigo de la "mano de obra desocupada" (represores de la última dictadura que se dedicaron al delito común en democracia). Al momento de su desaparición fue retratado como el primer desaparecido en democracia.

14 El hecho tuvo lugar el 8 de mayo de 1987. Tres jóvenes estaban reunidos en una esquina del partido de Lomas de Zamora cuando fueron atacados por tres policías que luego intentaron simular un enfrentamiento. Tras dos juicios (1990 y 1994) se condenó a los policías a once años de prisión. En memoria de este hecho se conmemora en el país el "Día Nacional de la Lucha Contra la Violencia Institucional". 
El fundamento de la legitimidad de las organizaciones de familiares nucleados en torno a la violencia policial es identificado por la autora en los lazos de sangre con las víctimas pero, además, la referencia a lazos familiares funciona (al igual que en el caso de las organizaciones asociadas al movimiento de derechos humanos históricos como Madres y Abuelas de Plaza de Mayo, H.I.J.O.S., Familiares de desaparecidos y detenidos por razones políticas, entre otras) como un eje que estructura la identidad del grupo. Este punto puede ilustrarse con la presencia de espacios como la Comisión de Familiares de la Coordinadora contra la represión policial e institucional, Familiares de víctimas indefensas - Mendoza (FAVIM), Comisión de familiares de víctimas indefensas de la violencia institucional (COFAVI), Familiares y Víctimas en Lucha contra la Impunidad en Democracia (FAVELCID) (Pita, 2004; Cuenca y Trincheri, 2010).

La persistencia de principios tradicionales (como los vínculos familiares), la apelación a una 'comunidad de sangre' en el marco de un Estado moderno y una continuidad entre las prácticas, organizaciones y memorias de los setenta y aquellas que se pueden encontrar en los activismos de hoy en día no son los únicos modos en los que estos activismos interactúan. Existen también los llamados "memoriales híbridos" donde convergen víctimas de violencia policial con otras del terrorismo de Estado (Vecchioli, 2005). La confluencia de estos actores disimiles se registra, por ejemplo, en el monumento-homenaje elevado en memoria de la Masacre de Flores (Rebollar, 2017). También sucede en el homenaje a Leticia Oliva en el memorial de Sebastián Nicora ${ }^{15}$. En ambos convergen en la esfera pública experiencias históricas y contemporáneas de sufrimiento, estableciéndose lazos de solidaridad entre las víctimas. A su vez, durante el acto de Punta Indio pudimos observar cómo desde un espacio de familiares víctimas de la violencia estatal se recurre a un consolidado repertorio de acciones característico de los activismos contra la violencia represiva de la última dictadura. La recuperación de la fórmula "Presentes, ahora y siempre" para evocar la memoria y la lucha

15 Durante 2017, impulsado desde Jóvenes y Memoria, vecinos de Punta Indio realizaron un homenaje a Leticia Oliva, detenida desaparecida en 1978 y víctima de los vuelos de la muerte. Su cuerpo, hallado en 1979 en la playa donde encontraron a Nicora, fue identificado en 2015. La conmemoración se desarrolló en el mástil elevado en memoria de Sebastián. 
de Sebastián y Fernanda Nicora demuestra cómo las experiencias de activismo no solo confluyen espacialmente sino que se sirven de un repertorio de prácticas compartidas.

A partir de lo indicado en el presente apartado estamos en condiciones de precisar a qué referimos cuando hablamos de "víctima". Dolor, lazos de solidaridad, intervención en la arena pública son elementos constitutivos de esta categoría. La misma es una figura paradójica, pasiva y con agencia colectiva a la vez, con un sufrimiento particular e incomunicable pero que representa un formidable catalizador de solidaridad social (Gatti, 2016).

Todo lo indicado hasta aquí permite recuperar el pasaje de una discursividad marcada por la violencia represiva a otra donde la violencia institucional comienza a intervenir en la arena pública, pasaje que hizo eco en diversas organizaciones de derechos humanos y de familiares. La RED de la CPM se inserta en este contexto en cuanto espacio de familiares conformado al interior de un organismo gestado en función de las violaciones de la dictadura. Su nominación inicial en términos de violencia institucional para luego pasar a llamarse por las violencias estatales da indicios de un estrecho diálogo con el modo en el que se conformó el campo.

\subsection{El camino de la RED: encuadramiento y distinción identita- ria. Nombres, dolor y sangre}

El espacio que compone la RED es, como vimos, de reciente creación ${ }^{16}$. Sin embargo, debe insertarse en un proceso de larga data iniciado en 2004 a partir del primer informe del sistema de la cruel-

\footnotetext{
16 Conforman la RED: la Asociación Civil Camino hacia al siglo XXII; los Colectivos de Familiares Masacre de Quilmes, de la Masacre de Pergamino, Dignidad (San Martín), de Lobos (Marta Gálvez), ACIFAD Asociación de Familiares de detenidos en Cárceles (Tandil- Olga Pendas y del Municipio de la Costa) y FADDET - Asociación de Familiares de detenidos y detenidas Tandil; los Colectivos de Familiares y Amigos de Florencia "China" Cuellar, Sebastián Bordón, Nazareno Vargas y Agustín Curbelo (Merlo); las Cooperativas Textiles Esperanza (San Martin) y Patagonia (San Martin); los Familiares de Andrea Viera (Eugenia Vázquez), Fabián Gorosito (María Viera), Omar Cigarán (Sandra Gómez), Pablo Alcorta (Emilia Vasallo) y los organizadores de la Marcha Nacional contra el gatillo fácil; el Comedor Los Pichoncitos (San Martín); el Consejo de Control Ciudadano Punta Indio; la ONG Yvy Porâ Tierra Fértil Educación en cárceles (Quilmes); la Coordinadora contra la impunidad policial de Avellaneda (Claudio Castro); FAVISIC Familiares de Víctimas del Sistema de la Crueldad; la Red de familiares víctimas de violencia institucional de Malvinas Argentina; FADELI - Asociación Civil de Familiares de Detenidos y Liberados (San Martín); y finalmente, la Organización de familiares Lázaro levántate y anda (La Matanza).
} 
La red de familiares contra la tortura y otras violencias estatales (CPM):

sangre y reencantamiento del activismo.

dad y el acercamiento de la CPM con organizaciones y familiares víctimas de la violencia estatal (Raggio y Cipriano García, 2019). Para su abordaje ahondaremos en su modo de organización en red, en la relación de encuadramiento y tensión con la CPM, en la importancia del cambio de nombre y el lugar que ocupa el dolor y la sangre en la retórica de sus referentes.

\subsubsection{Organización y tensiones}

La idea de una red refiere a relaciones de horizontalidad entre los integrantes, sin embargo, en la práctica diversos actores adjudican a Cipriano García el liderazgo del espacio o subordinan la red a la estructura de la CPM:

"Al crearse la Red de Familiares contra la Tortura y otras Violencias Estatales es como que somos hijos de la CPM porque depende de ellos, ellos son los que la coordinan, ellos son los que nos dan una mano, son ellos los que nos asisten y nosotros tomamos ese conocimiento y experiencia y la bajamos en el territorio" (Entrevista a referente de FADELI, 12/2/19).

Esta dependencia institucional, aludida a través de la metáfora filial, se hace eco del esfuerzo de "encuadramiento" (Pollak, 2006) por parte la CPM que ubica su preocupación por estos temas en el pasado dictatorial:

"Durante la última dictadura, surgió un actor político nuevo en la Argentina: las organizaciones de familiares de presos políticos y los desaparecidos (...). Esta experiencia demostró que del dolor puede salir la fuerza para transformar la realidad a través de la organización y la acción política. Desde la CPM, desplegamos acciones para acompañar a las familias víctimas de lo que hemos llamado el "sistema de la crueldad", constituido por las prácticas violentas de las policías, las fuerzas penitenciarias y la justicia que son violaciones sistemáticas de los derechos humanos (...). En el marco de múltiples acciones contra estas violencias (...) en febrero de 2017 se creó formalmente la Red de familiares contra la Tortura y otras Violencias Estatales (RED) en la provincia de Buenos Aires. (...) Hoy 
los familiares que luchan contra la tortura y las violencias estatales son un nuevo actor del movimiento de derechos humanos" (Red de familiares contra la Tortura y otras Violencias Estatales, CPM, Boletín sin número, sin fecha). ${ }^{17}$

De este modo tanto los miembros de la RED como la CPM colaboran en la construcción de un sentido común que identifica a la violencia institucional como heredera directa de la dictadura (Vecchioli y Leal, 2017). Sin embargo, ante la caracterización de los integrantes de la RED como actores novedosos, miembros de esta organización se resisten a ser catalogados como los "recién llegados" y marcan distancia con el relato oficial de la CPM y sus intentos de encuadramiento En este sentido, miembros de la RED recuperan la identidad que construye para sí la CPM y en el proceso, mitigan la supuesta novedad de las luchas contra las violencias estatales:

"En aquellos momentos [durante la dictadura] (...) se perseguían, torturaban, mataban, hacían desaparecer a los que ellos creían las células, al organizador y, después, se la agarraban con cualquiera. Se quería matar una ideología, una idea, la política, porque la política es una idea (...). Hoy se quiere exterminar a una clase, hoy ya no se mata una idea política, hoy se trata de matar o se trata primero de estigmatizar, de etiquetar a alguien que es delincuente, que robó. Este tiene color de piel, negrito, morochito, tiene arito, tiene tatuaje, se viste de una manera... hoy se trata de exterminar a una parte como quisieron hacer en aquel momento." (Entrevista a referente de FADELI, 12/2/19)

En esta disputa por el lugar en el campo, emerge paradójicamente un efecto de memoria que omite la condición de clase de la mayoría de los desparecidos (al menos el 30\%), descriptos por la CONADEP (1984) como obreros, poniendo en evidencia la tensión de clase entre los familiares que hegemonizaron el campo de los derechos humanos - mayormente provenientes de las llamadas clases medias- y estos otros ubicados en el lugar de "recién llegados" más ligados a los sectores populares.

17 El material fue entregado en mano por un miembro de FADELI quien indicó que este era el primer boletín que la CPM emitía tras el cambio de denominación de la RED. 
La red de familiares contra la tortura y otras violencias estatales (CPM):

sangre y reencantamiento del activismo.

Estas disputas conviven con la utilización de conceptos como "exterminio" para referir a las prácticas represivas y/o letales utilizadas por el Estado en democracia, lo cual deja entrever cómo la experiencia dictatorial influyó en las experiencias de sufrimiento de otras víctimas. Mientras que a la primera le cabe el término de exterminio, dado el carácter sistemático de ocultamiento y desaparición de los cuerpos, es más forzada su utilización en democracia. Aunque la desaparición como modalidad represiva se encuentra vigente, como evidencian escandalosamente los casos emblemáticos de Jorge Julio López, Luciano Arruga y Santiago Maldonado, ${ }^{18}$ entre otros; sin embargo, esta modalidad no es masiva ni es la práctica represiva dominante.

\subsubsection{Encuadramiento y nominación}

A partir del 2004 comienzan a establecerse relaciones entre la CPM y organizaciones de familiares por fuera de los casos de violencia represiva ligada a la dictadura. La CCT y sus informes anuales cimentaron este viraje. Fue recién en 2015 cuando la CPM institucionaliza estos vínculos a partir del lanzamiento de una serie de cinco encuentros nacionales y surge un primer nombre para la RED.

El primero de los encuentros se desarrolló el 22 de junio de 2015 en La Plata. Allí se buscó avanzar en la construcción de una agenda común; ocupó un rol central el relato de las experiencias de los familiares y el debate y puesta en común de posibles estrategias a seguir. El segundo se desarrolló en noviembre de 2015 y contó con la presencia de Nora Cortiñas, en calidad de miembro notable de la CPM. Su interpelación a "no bajar los brazos, no encerrarse en el dolor, apostar a la lucha porque solo la lucha y la memoria de las víctimas sana y solo la organización puede conquistar derechos" (Red de familiares, s.f.) permite entender la centralidad del dolor como discursividad propia de estos espacios y la propuesta de la CPM de

18 López fue víctima de desaparición forzada durante la dictadura y en el marco de los Juicios por la Verdad se presentó a declarar y fue desparecido antes que se dictara sentencia. en 2006. Al día de la fecha se sigue sin conocer su paradero. Arruga fue un joven que estuvo desaparecido durante cinco años (2009-2014) tras haber sido detenido por la policía bonaerense; su causa solo cuenta con un condenado, Diego Torales, quien fue juzgado por las torturas realizadas a Luciano meses antes de su desaparición. Maldonado (remite a un caso de desaparición seguido de muerte que se dio en el marco de la represión de la Gendarmería Nacional a una protesta de la comunidad mapuche Pu Lof. 
transformarlo en un recurso para impulsar la lucha cívica. Para la Comisión, "si el primer encuentro permitió trascender el dolor para pensar las múltiples violencias del Estado y vincular ese dolor como producto de un sistema estatal que viola sistemáticamente los derechos humanos, (...) el segundo (...) permitió trascender el diagnóstico y pensar herramientas para luchar contra la impunidad" (Red de familiares, s.f.).

En el tercer encuentro nacional (2016) lo novedoso fue la concurrencia de referentes de organizaciones de otros países latinoamericanos. Fue en el cuarto aniversario de la muerte de Sebastián Nicora que se crea la Red de organizaciones de Familiares contra la Violencia Institucional (RED), luego del cual se llevó a cabo el cuarto encuentro nacional. En 2018 se celebró el quinto encuentro y se decidió cambiar el nombre de la RED.

"Fue después de un proceso largo de cinco años, desde el 2012 al 2017, que la comisión toma la decisión de encuadrar a todas las organizaciones bajo un nombre simbólico, que fue Red de Familiares Víctimas de Violencia Institucional. El año pasado, el 15 de diciembre, se le cambió el nombre por Red de Familiares contra la Tortura y la Violencia Estatal. (...) la Comisión decidió cambiarle el nombre en común acuerdo, a partir de varios talleres que tuvimos." (Entrevista a referente de FADELI, 12/2/19)

Este cambio de nombre no fue percibido como abrupto. Fue vivido como un proceso "acordado" que permitió a los adherentes de este espacio conservar el sentimiento de identidad y pertenencia. A su vez, el hecho de que la misma sigla "RED" siguiera funcionando ayudó a transitar ese cambio. Ahora bien ¿cómo interpretar el cambio de nombre?

Desde nuestra perspectiva, el pasaje de violencia institucional a violencia estatal entabla un diálogo con la discursividad de la Coordinadora contra la Represión Policial e Institucional (CORREPI), la cual, más allá de su nombre, se ha esforzado por instalar públicamente la interpretación de estas violencias como prácticas que caracterizan el accionar del Estado (Perelman y Tufró, 2016). En el marco de un gobierno de turno donde las políticas e intervenciones 
La red de familiares contra la tortura y otras violencias estatales (CPM): sangre y reencantamiento del activismo.

de corte punitivista se vuelven cada vez más frecuentes, el cambio de nombre por uno más cercano al discurso abiertamente confrontativo de CORREPI permite reinterpretar las lecturas clasistas de uno de los referentes de FADELI y esbozar que esta tónica permite a los actores de la red no solo aceptar sino capitalizar el nuevo nombre.

\subsubsection{El dolor como fuente de legitimidad y articulador del activismo}

En todo momento el dolor fue un elemento central para este espacio. La superposición e interacción de violencias a las que este "sistema de crueldad" expone a los familiares víctimas emerge con claridad en los relatos de los entrevistados y visibiliza esta dimensión:

"El dolor nos hizo vincular y también aprender los derechos que tiene cada uno. Si bien ellos están detenidos [los familiares] el Estado solo les quita la libertad, el resto de los derechos se mantienen. A veces como familiar te cuesta mucho darte cuenta que tenés que hacer valer el derecho [al Estado]. Te hablo de cosas básicas, la atención médica. (...) Son las largas esperas, yo creo que también es una forma de tortura el estar esperando una condena tanto tiempo" (Entrevista a referente de la Cooperativa Esperanza, 14/2/19).

Como vemos el dolor es el punto desde el cual la ciudadanía entra en escena. Mediante una experiencia dolorosa como la privación de la libertad de una persona allegada, aprehenden el resto de las garantías y derechos que les corresponden por su sola condición de persona humana. El dolor se presenta como un medio para el reclamo y ejercicio de derechos. Desde el dolor se justifica también el imperativo de lucha para afrontar el duelo y las injusticias a las que miembros de la RED se enfrentan:

"Tenemos que transformar ese dolor en un aprendizaje, en una construcción, un desarrollo, transformarlo en marchas, transformar el dolor que vive cada familia en lucha, no en odio (...) ese dolor se transforma en lucha cuando lo unís con otras personas o con otras organizaciones o con una estructura como la CPM. El dolor hay 
que transformarlo en resistencia y lucha." (Entrevista a referente de FADELI, 12/2/19).

Las palabras de este referente recuerdan a las de Cortiñas al remitir al mandato de "no encerrarse en el dolor". Esta gestión del dolor no es de dominio exclusivo de los casos de violencia estatal. Al abordar el caso de los familiares de las víctimas de Cromañón ${ }^{19}$, Zenobi (2010) demuestra cómo se buscaba recomponer a los "familiares abatidos" para que participaran de la lucha y no se encerraran en su dolor. Mediante este ejemplo podemos observar la transversalidad que la gestión del dolor adquiere a la hora de pensar los activismos de familiares de víctimas y la lucha cívica que desarrollan.

\subsubsection{La triple connotación de la sangre}

Para finalizar nos resta recuperar un elemento: la sangre. Los lazos de sangre han sabido ganar un legítimo lugar en los reclamos de colectivos de familiares desde la vuelta de la democracia en nuestro país (Vecchioli, 2005) y con el pasar de los años la influencia de dichos lazos se ha extendido al propio Estado (Vecchioli, 2018). Sin embargo, los significados atribuidos a la sangre, trascienden en este caso el lugar de los lazos de biológicos y/o de parentesco y emergen nuevos usos que permiten profundizar el análisis. Son ilustrativas las palabras de una referente de la Cooperativa Esperanza que integra la RED:

"Mi hijo la primera vez que cae detenido cae en la 23 de Florencio Varela hay una pelea, el sale lastimado y estuvo tres días desangrándose en los buzones sin atención médica, me llama porque ya no daba más y se le estaba infectando la herida y me dice "mamá, me dieron este número que es de derechos humanos, estaba escrito en la pared con sangre de otra persona que habia pasado por los buzones, proba ya", y me atiende Roberto [Cipriano]. (...) Yo hablaba constantemente con él, ni siquiera sabía que [él] era 'la CPM'." (Entrevista 14/2/19. Resaltado propio).

Aquí, la consanguinidad no se presenta como único motor del

19 El 30 de diciembre de 2004 en el establecimiento República de Cromañón (Once, Buenos Aires), durante el recital de la banda musical Callejeros se desató un incendio que dejó 194 muertos y más de 1400 heridos. 
La red de familiares contra la tortura y otras violencias estatales (CPM): sangre y reencantamiento del activismo.

activismo; si bien esta presente, nos encontramos con un triple registro. El lazo familiar se mantiene como primer nexo; un hijo que se comunica con su madre buscando socorro. La sangre de la víctima, un sujeto desangrándose constituye la segunda imagen. Finalmente, la sangre de un tercero desconocido en las paredes del lugar donde lo tenían aislado se presenta como un instrumento para acceder a "derechos humanos".

La sangre como lazo, la sangre de la víctima y la "sangre de los derechos humanos". Esta superposición de imágenes va desde el nombre propio al anonimato. Particularmente, la tercera de ellas, es "una sangre" de procedencia completamente anónima y funciona, al igual que en el caso del dolor, como un medio para la lucha por derechos. Pero, además, cumple el papel de nexo entre los sujetos que ven violados sus derechos y los organismos de derechos humanos. Ante una ciudadanía violentada, la sangre se presenta como una herramienta de cuidado entre pares para afrontar las prácticas de tortura ejecutadas desde el servicio penitenciario.

A su vez, estos nuevos significados de la sangre pueden interpretarse a la luz de los criterios clasistas que rigen detenciones y encarcelaciones (Bonvillani, 2017; Rodríguez Alzueta, 2012). El hecho referido en el testimonio citado se distancia de la retórica más extendida entre los familiares de clase media que protagonizaron los activismos asociados a la dictadura. Aquí la sangre anónima inscripta en las paredes carcelarias permite acceder a la CPM y entabla una solidaridad de clase entre activistas y víctimas: sus sangres se mezclan en la misma celda. Este hecho particular cobra así una fuerza sorprendente que excede a la lógica que encasilla a la sangre como un principio de vinculación tradicional. La sangre, en las tres variantes que esta imagen nos presenta, impulsó el activismo de familiares. Esto obliga a repensar el papel que la misma tiene al interior de los relatos de familiares y víctimas. Estos sentidos conviven con otros propios del mundo religioso, donde las víctimas concebidas como "mártires" son "semilla de resurrección". En este marco, cobra sentido el análisis de la organización católica Lázaro levántate y anda (La Matanza), integrante de la RED. 


\section{LA ORGANIZACIÓN "LÁZARO LEVÁNTATE Y ANDA" (LA MATANZA)}

Hasta este momento hemos podido observar como lo religioso esta imbricando la CPM, funcionando desde los inicios como una infraestructura que dota de legitimidad al accionar de la Comisión y aporta un capital militante más dentro del campo secularizado de los derechos humanos. A partir de un caso testigo, la Organización "Lázaro Levántate y anda" (La Matanza) (en adelante LLyA) veremos cómo lo religioso adopta mayor importancia, dando nuevos sentidos al activismo. Si bien desde la misma nominación del espacio se explicita un repertorio cristiano, la reconstrucción de la trayectoria de la fundadora, Blanca Careaga, y de la historia de la organización son elementos fundamentales a tener en cuenta. El tránsito de Careaga puede pensarse de la siguiente manera: de víctima a activista, de activista a experta y, finalmente, de experta a dirigente de una organización propia

\subsection{Lázaro ¡levántate $y$ anda!}

El nombre de la organización remite al "milagro de la resurrección de Lázaro de Betania", relatado en el texto bíblico de la tradición cristiana.

La idea general del dogma católico presenta a los milagros como "fenómenos extraordinarios, singulares, perturbaciones del orden natural" generados por intervención divina con el fin de probar y confirmar la palabra y eficacia de Dios. Sin embargo, más que pruebas que fundamentan la creencia religiosa pueden ser entendidos como el producto de un determinado punto de vista religioso (Mejía, 2006). Siguiendo a Costilla (2016) y partiendo de una conceptualización de los fenómenos religiosos como hechos sociales polisémicos, y del milagro como construcción social, lo milagroso representa una vía de entrada para el análisis de lo social. Los milagros permiten no solo generar sino también canalizar diversos significados, los cuales son presentados de manera estratégica por diversos actores sociales.

La resurrección de Lázaro es un pasaje de la Biblia que ha trascendido los estudios meramente teológicos y ha permeado el dis- 
La red de familiares contra la tortura y otras violencias estatales (CPM): sangre y reencantamiento del activismo.

curso político de la Argentina, un país de mayoría católica y donde desde comienzos del siglo XX se volvió hegemónica una modalidad de ser católico: el catolicismo integral, que, lejos de concebirse relegado a la sacristía, interviene públicamente en la política nacional como un actor más, naturalizado (Mallimaci, 2013).

A tal punto, sus actores y su repertorio de símbolos tiene eficacia en la arena política que un convertido al catolicismo, como el ex presidente Carlos Saúl Menem, bautizado para poder asumir el cargo presidencial, utilizaba elementos constitutivos del imaginario judeocristiano en sus discursos políticos (Arias, 1996; Campos, 2009). En su discurso de asunción a la presidencia el 8 de julio de 1989, Menem no solo pronunció en reiteradas ocasiones "Argentina, levántate y anda”, equiparando de esta manera a la Nación con Lázaro y a sí mismo con Jesucristo, sino que además reforzaba una imagen mesiánica de su presidencia (Lasso, 2008). La esfera de la política, al igual que en los orígenes del campo de los derechos humanos en la Argentina, es en general asociada con principios seculares, sin embargo, en la práctica, registramos la presencia vigente de lo religioso.

Lo anterior ejemplifica solo uno de los usos e interpretaciones de "la resurrección de Lázaro" en el escenario nacional. En el caso que ha despertado nuestro interés, la organización Lázaro levántate $y$ anda, los sentidos que emergen no pueden disociarse del territorio en el que se desarrollan.

\subsection{La Matanza}

El partido de La Matanza es el Municipio más extenso y el más poblado del Área Metropolitana de Buenos Aires y se ubica en la zona suroeste del conurbano bonaerense, provincia de Buenos Aires. Su territorio se ve atravesado a su vez por tres cordones del conurbano.

La violencia es un componente fundacional de este territorio y su nombre deja entreverlo. Múltiples hipótesis se barajan sobre el origen de su denominación, aquellas que más se remontan en el tiempo remiten al año 1536, con la llegada de Pedro de Mendoza al Río de la Plata. Tras el combate de Corpus Christi fallecieron varios de sus familiares (Latini, 2011) dando el nombre del "lugar de la matanza" 
al espacio en el que esto sucedió.

Hasta las primeras décadas del siglo XX La Matanza se caracterizó por el predominio de las actividades agropecuarias (Pomés, s.f.; Serra, Durán y Penella, 2015). Entre 1914 y 1947 atravesó un proceso de periurbanización. De 1947 a 1960 aconteció un proceso de industrialización que erigió al municipio de La Matanza como uno de los centros industriales más relevantes del país (Dawyd, Mancini, Medina, Pantanetti, y Díaz Hlavka, 2014). Finalmente, de la mano de una desaceleración del crecimiento, estancamiento y el impacto del paquete de políticas neoliberales de los años noventa, nos encontramos con una etapa de concentración de la tierra (19602000) (Svetliza de Nemirovsky, 2002) o, en términos de Pomés (s.f.), de fragmentación social y desindustrialización (1976-2003).

Su condición de centro industrial condujo a que La Matanza fuera el escenario sobre el que una gran variedad de experiencias organizacionales tuvieron lugar. Recordemos que el sector ocupacional con mayores desaparecidos fue el de los obreros, la crudeza con que la última dictadura azotó este territorio no es casual.

Los conflictos metalúrgicos y las experiencias de militancia y lucha sindical que se registraron en La Matanza, las experiencias de fabricas recuperadas (Arias, Fonseca y Garcia Allegrone, 2004), las tomas de tierras y asentamientos (Woods, 2007) y las experiencias asociadas a organizaciones piqueteras (Manzano, 2007) permiten dar cuenta de un sostenido accionar organizacional y de un activismo de la protesta en el territorio.

Respecto a conflictos sociales y territoriales (toma de tierras, asentamientos, organizaciones piqueteras) Woods (2007) y Manzano (2007) dan cuenta del peso que va adquiriendo la Iglesia Católica al momento de articular con estos espacios. A través de prácticas realizadas en el marco las Comunidades Eclesiales de Base (CEB) se volvió cada vez más común la presencia de actores religiosos en dichos reclamos. Si bien el caso de Alberto Spagnolo y su participación enmarcada en el Movimiento de Trabajadores Desocupados (MTD) de Quilmes resulta paradigmático (Donatello, 2002), en el territorio de La Matanza la presencia de referentes religiosos interviniendo en conflictos sociales también fue relevante. 
La red de familiares contra la tortura y otras violencias estatales (CPM): sangre y reencantamiento del activismo.

Los índices de pobreza e indigencia son una característica que no se puede pasar por alto al hablar de La Matanza. El Observatorio de la Deuda Social Argentina-Universidad Católica Argentina (ODSA-UCA), emitió un informe en 2018 que da cuenta de las gravísimas dimensiones que estos dos indicadores han adquirido, afectando particularmente al conurbano bonaerense. En lo que respecta a los porcentajes de indigencia del conurbano, entre 2010 y 2018 el porcentaje de hogares paso de de $4,7 \%$ a $6,3 \%$ y en personas de $7,5 \%$ a $8,9 \%$. Por otra parte, la pobreza en hogares aumento casi en diez puntos (de $25,6 \%$ a $34,6 \%$ ) mientras que en personas el pasaje fue de $36,1 \%$ a $43,4 \%$.

Según datos del Registro Público Provincial de Villas y Asentamientos Precarios (RPPVAP) de la Subsecretaría Social de Tierras, Urbanismo y Vivienda bonaerense, en 2017 La Matanza contaba con 115 barrios de emergencia registrados, ubicándose solo por detrás de La Plata (129 asentamientos). El sostenido porcentaje de pobreza y la segregación territorial que se percibe al interior del partido denotan porque es necesario tener presentes los datos recuperados y es que, como señalo Tiscornia hace décadas:

"los hechos de violencia policial que resultan en muertes y abusos son producidos sistemáticamente, y son, en una proporción considerable, un modus operandi institucionalizado de las fuerzas policiales (...) su característica principal es que son aplicados fundamentalmente sobre aquellos grupos o personas que, pertenecientes a sectores pobres, transitan el ambiguo y anchuroso espacio de la ilegalidad." (1998, p.126)

Los comentarios de la referente de Coordinadora contra la Represión Policial e Institucional (CORREPI), María del Carmen Verdú, se complementan con lo expuesto. Al dar un adelanto del archivo de casos de 2018 ofrece una imagen del escenario actual:

"Por un lado tenemos una política de saturación y militarización de los barrios, donde vemos en cada esquina la presencia de tres o cuatro fuerzas distintas. Ese incremento de poder de fuego en la calle es lo que incrementa los casos de gatillo fácil. Por otra parte, tenemos una mayor cantidad de detenciones, los casos por 'abuso de autoridad' se 
han multiplicado, esa mayor circulación de personas en comisarías desbordadas explica el aumento de las muertes" (Lag, 3/1/2019)

Ahora bien, según uno de los últimos informes elaborados por la CPM, de los 90 casos de muertes de personas bajo custodia de los que pudieron obtener datos, el 11\% aconteció en La Matanza, ubicándose tercero en el listado. Del departamento judicial de La Matanza provienen el 12\% (67 casos de 553) de las causas iniciadas a jóvenes. Respecto a los casos de violencia letal policial, sobre un total de 122 casos registrados, 9 tuvieron lugar en este territorio (CPM, 2018).

Todo esto tiene además por marco explicativo el pasaje de un Estado de Bienestar a uno de Malestar (Rodríguez Alzueta, 2014) el cual ancla su legitimidad en la protección contra peligros referidos a la seguridad personal y que requiere de constantes chivos expiatorios que interpelen al imaginario policialista y permitan su funcionamiento: un consenso social que al servicio del dispositivo de temor y control construye a un otro estigmatizado.

Tanto las condiciones de pobreza e indigencia como las prácticas ilegales ejercidas por las fuerzas de seguridad permiten articular el activismo de organismos de derechos humanos con un activismo asociado al catolicismo. Ya sea enlazando la violencia represiva de la dictadura con la violencia estatal en democracia o partiendo de una estrategia integral de defensa de la dignidad humana por medio de la cual se erigen desde espacios católicos contra las "nuevas" víctimas del neoliberalismo (Catoggio, 2016a, p.229), el territorio de La Matanza configura un sitio de muerte signado por la violencia estatal atravesado a su vez por desalentadores indicadores económicos. En este escenario marcado por la muerte, cobra sentido una organización que acude a la figura del "milagro de la resurrección" para motivar el activismo como hace LLyA.

\subsection{La organización Lázaro levántate y anda}

\subsubsection{De víctima a activista}

La recuperación de la trayectoria de una de las fundadoras de LLyA, Blanca Careaga, es crucial para poder comprender el ac- 
La red de familiares contra la tortura y otras violencias estatales (CPM):

sangre y reencantamiento del activismo.

cionar de la organización. Para entender las formas que adquirió el activismo de Careaga a lo largo del tiempo (y el impacto del mismo en LLyA) partimos de un punto común con Pereyra Iraola y Zenobi (2016) quienes, al recuperar los postulados de Bourdieu y Fillieule, indican que lejos de presuponer una coherencia y continuidad de los recorridos biográficos, los comportamientos y actitudes de los actores están condicionados en cada etapa de su vida por situaciones y decisiones del pasado y los contextos en los que se encuentran insertos (p.28).

Blanca Careaga, nació en Paraguay y creció en el seno de una familia católica practicante. ${ }^{20}$ En 1976 abandonó Paraguay, país azotado por la dictadura de Alfredo Stroessner, y migró hacia la Argentina, a dónde llegó con dieciséis años junto a su hijo de ocho meses para instalarse en la Quema de Bajo Flores. ${ }^{21}$

En Argentina, durante los años de la dictadura, tuvo un rol activo en la organización de sus vecinos. A pesar de haberse encontrado amenazada por el accionar represivo en las villas, Careaga remarca que ella viene de:

\begin{abstract}
“una sangre que es medio revolucionaria que es mi papá, mi papá era médico revolucionario, mi papá y algunos parientes más, entonces yo soy así, muy activista, la injusticia... no puedo permitir que los niños, que los adolescentes lloren, sufran (...). Participaba de un espacio de vecinos en riesgo que nos poníamos de acuerdo que cuando venían los camiones militares nos teníamos que avisar uno a uno (...) No me alejé durante la dictadura, no formé ningún espacio pero avivé giles, siempre conversaba, miraba, decía de usar estrategias (...). Después ya nos perseguían, nos querían echar a cada uno a nuestro país a los extranjeros, la persecución era terrible". (Entrevista a Blanca Careaga, 18/2/19. Resaltado propio)
\end{abstract}

\footnotetext{
20 Ella contrajo matrimonio por Iglesia en 1975 e inculcó en sus hijos el catolicismo. Una de sus abuelas tenía a su cargo un oratorio destinado a la Virgen de Caacupé. La Virgen del oratorio pertenece a su familia y se hereda entre sus integrantes. Actualmente está bajo el cuidado de la hermana mayor de Blanca.

21 "La Quema" es como se conocía a los vaciaderos a cielo abierto. En 1977 la Municipalidad de la Ciudad de Buenos Aires y el Gobierno de la Provincia de Buenos Aires crearon la Coordinación Ecológica Área Metropolitana Sociedad del (CEAMSE) buscando resolver la disposición final de los residuos y ampliar la superficie de los espacios verdes. Esto significó el cierre de los vaciaderos conocidos como "la Quema". Junto a estas acciones tuvieron lugar otros procesos urbanísticos: un nuevo código de edificaciones, autopistas, estacionamientos privados y el programa de erradicación de villas (Cosacov, Perelman, Ramos y Rodríguez, 2012)
} 
En este ejercicio de memoria, Careaga comienza a construir las bases sobre las cuales legitimar su activismo. Haciéndose eco de la importancia que cobraron los lazos familiares para organizar el activismo durante la dictadura militar y del esfuerzo que realizaron luego los organismos de derechos humanos para mantener estos lazos con las víctimas para legitimar su accionar (Jelin, 2006), Careaga evoca el vinculo familiar para legitimar su propio activismo, aunque claro está, no lo hace a partir de la figura de las víctimas.

Aquí la sangre puede interpretarse en términos de herencia y linaje (Catoggio, 2016a). Criada en un ambiente familiar católico y con un fuerte ejemplo paterno, esta sangre que circula por sus venas y que encarna una voluntad "revolucionaria", "de servir a los demás", traspasada de generación en generación la "destina" a su activismo, como una consecuencia natural.

A su vez, Careaga, nos cuenta que comparte apellido (y parentesco lejano) con una de las fundadoras de Madres de Plaza de Mayo: Esther Ballestrino de Careaga. Este parentesco, aunque tardíamente descubierto, refuerza la idea de destino del activismo.

Sin embargo, en este punto la sangre no emerge como un componente central, sino el apellido de la familia política compartida. Si bien nuestra entrevistada no participó en la constitución del campo de los derechos humanos en el país, los lazos con una fundadora de Madres de Plaza de Mayo (o más precisamente, con su familia política) insuflan a su patronímico, cuando menos parcialmente, con la autoridad de uno de los más relevantes espacios nacionales de activismo en derechos humanos.

Más allá de lo simbólico, el relato de los primeros años de su trayectoria de vida en la Argentina permite notar cómo su carrera en términos de activismo en derechos humanos no se corresponde con la experiencia formadora del campo en la región. Ella no fue parte de este proceso constitutivo encabezado por las clases medias, por esta razón su relato remite a diversas figuras que legitimen su activismo. Además, su experiencia tampoco se configura en un comienzo en torno a la condición de víctima o de familiar de una víctima del terrorismo estatal.

Como hemos visto hasta aquí, el activismo de Careaga se centra en un ámbito vecinal asociado a los intentos de erradicación de las villas de emergencia. Ahora bien, ella no vivió durante mu- 
La red de familiares contra la tortura y otras violencias estatales (CPM):

sangre y reencantamiento del activismo.

chos años en este territorio, al poco tiempo se mudó al barrio de La Boca, ${ }^{22}$ donde vivió durante casi tres décadas para luego instalarse definitivamente en Laferrere, partido de La Matanza.

Durante muchos años continuó participando y activando la organización vecinal hasta el año 2000 cuando una experiencia de violencia en carne propia la llevó a asumir la condición de víctima y reconfiguró su activismo. Según nos relató, se trató de una situación de violencia de género que afectaba a ella y a su grupo familiar, incluidos sus hijos:

"Por lo que me pasó, 'lo de la violencia de género' de mi ex marido en el año 2000, decidí que tenía que ayudar a la Argentina, y a las mujeres. Lo que me pasó fue terrible, yo de milagro estoy viva, eso fue lo que me llevo a ayudar tanto" (Entrevista a Blanca Careaga, 18/2/19. Resaltado propio).

Esta experiencia la motivó a crear la organización Abriendo Rejas (espacio que luego cambiara su denominación por la de LLyA).

"Abriendo rejas simbolizaba para mí que, después de tantos años de violencia de género contra mi persona, yo me sentí liberada. Cuando fue la jueza y el fiscal a mi casa con todos los patrulleros, yo te juro por Dios que no te miento, yo sentí como que se me liberó un portón que se me abrió una reja, yo estaba presa (...) lo asimile así, me agarro una libertad..." (Entrevista a Blanca Careaga, 18/2/19).

Esta situación marca un punto de inflexión para Careaga y su activismo. No solo permite observar la multiplicidad de violencias que atraviesan su vida, sino que además introduce la figura del "milagro" con clave para procesar la propia experiencia traumática. Esta experiencia límite resulta disparadora para la reconfiguración de su carrera activista. A partir de entonces, no solo crea una organización para "ayudar a otros" sino que busca formarse como experta.

22 El barrio de La Boca se ubica en el sector sur de la ciudad de Buenos Aires, junto a la ribera del Riachuelo, y se conformo durante el primer período de metropolización de la Ciudad de Buenos Aires (1860-1914). Las actividades portuarias e industriales que históricamente se desarrollaron alrededor del río dotaron a este barrio de un perfil marcado por la presencia de inmigrantes, trabajadores y sectores populares. La precariedad y deficiencia de sus servicios públicos e infraestructura supo ser otro rasgo característico del barrio (Herzer, Di Virgilio, Guevara, Ramos, Vitale, e Imori, 2011; Thomasz, 2016). 


\subsubsection{De activista a referente con expertise}

Careaga comenzó un recorrido de ascenso social al comenzar a formarse en Derecho, a partir del contacto con el área de extensionismo jurídico de la Universidad Nacional de Lomas de Zamora (UNLZ) (Entrevista a Blanca Careaga, 18/2/19).

"En el año 2000 yo tenía mi consultorio en mi casa, en el barrio Las Juanitas, un consultorio jurídico avalado por la universidad de Lomas de Zamora, una extensión que nos bajó en los barrios las cuatro ramas de la Abogacía, Derecho Penal, Civil, Laboral, Constitucional, todo, nos formó en los barrios, y de paso yo también me forme en la Universidad con el mismo diploma. Yo en todo ese ínterin me capacité, estudié en la UBA, en la Universidad Austral, tome capacitaciones de liderazgo y entre todo eso, me capacité para asesoramiento." (Entrevista a Blanca Careaga, 18/2/19).

No es casual que su espacio de formación haya sido la UNLZ. Si bien no fue señalado por Careaga, en esta Universidad, al fragor de las leyes Blumberg, se desarrollaron una serie de prácticas de extensión jurídica: en 2004 se creó el Centro de Estudios de Política Criminal y Derechos Humanos (CEPOC) (Zenobi, Pérez, Galarza, Castro, Mansilla, Moreira, Barrios, Vanacor, Luján y Luque Wickham, 2014; Zenobi, Pérez, Lombraña, Lastiri y Liendro, 2015), en 2005 inició el programa de Alfabetización jurídica y en 2006 se fundó el Servicio de Asistencia Jurídica Gratuita y el programa de Extensionismo Jurídico Vecinal.

Como abogada, Careaga se especializa en "Familia" y en "Penal", dos áreas que le permiten transformar las violencias pasadas en un saber experto y un capital propio para su organización activista. La formación y el espacio por el que transitó Careaga le permitieron capacitar a nuevos miembros de la organización acceder a redes de sociabilidad que la vincularon con la Defensoría del Pueblo y con la CPM.

Particularmente su vínculo con la CPM se concreta en 2005; momento desde el cual su organización comenzó a relacionarse con las áreas de Jóvenes y Memoria y el Comité Contra la Tortura. En este contexto, y adelantándonos al siguiente apartado, Abriendo Rejas cambió su denominación por la de LLyA. 


\title{
5.3.3. El cambio en la nominación y la explicitación del componente religioso
}

Una vez que comenzaron a transitar los espacios asociados a la CPM, los objetivos de la organización se vieron atravesados por un nuevo contexto, que los llevó a diversificar sus aéreas de interés originales:

\begin{abstract}
"trabajamos con las mesas de admisión para la familia entera (...) trabajamos bajo el paraguas de 'JóvenesXJóvenes' y con la asociación civil de Laura Chamorro, y participamos en la Mesa territorial de Niñez y Familia del municipio [de La Matanza, Secretaria de Desarrollo Social]. Ahí llegan casos de niños y jóvenes en peligro y yo lo trabajo en red con el Comité Contra la Tortura. Trabajó con 'Jóvenes y Memoria' también, lo bajamos en 2008 en La Matanza; comenzamos a contar [sobre el programa] en cada colegio y empezaron a participar. Con ENVIÓN también articulamos y con 'Ojos despiertos." ${ }^{\text {'23 }}$ (Entrevista a Blanca Careaga, 18/2/19. Resaltado propio).
\end{abstract}

A primera vista "jóvenes en peligro" representa un enunciado confuso, pero al avanzar en el diálogo con Careaga, surgen casos de hostigamiento policial, irregularidades en procedimientos o abusos de poder que permiten comprender el sentido del trabajo conjunto que llevan adelante con el CCT. Además intervienen ocasionalmente ante casos de gatillo fácil que tienen lugar en el territorio.

Lo descripto hasta este punto configura una acotada reconstrucción de las dimensiones en las que interviene la organización una vez se vincula a la CPM. Ahora bien, al comenzar a transitar es-

23 Las mesas territoriales de la Secretaria de Desarrollo Social implican la participación de actores municipales, instituciones sanitarias, educativas y sociales, vecinos, organizaciones sociales y referentes barriales. Todas las áreas de la Secretaría cuentan con estas mesas, apostando a generar las soluciones requeridas en el territorio junto a la comunidad. En el marco de la Secretaria y su eje de Niñez, Adolescencia y Juventud, un conjunto de servicios y programas conforman el Sistema Integral de Promoción y Protección de Derechos de Niños, Niñas y Adolescentes (SIPPD), entre ellos el programa municipal PODÉS (Programa de Orientación y Desarrollo Educativo Socio comunitario) y el programa provincial de Responsabilidad Social Compartida ENVIÓN, los cuales funcionan articuladamente y cuentan con una extensa presencia territorial en el Municipio. ENVIÓN comprende espacios de acompañamiento individual y familiar destinados a llevar adelante la inclusión social de jóvenes vulnerables de entre 12 y 21 años. Envión Podes Ojos Despiertos es uno de los espacios donde funcionan estos programas. La organización JóvenesXJóvenes es caracterizada por Careaga como un espacio que busca incluir a jóvenes desclasados. Laura Chamorro es responsable de uno de los grupos de la Agrupación Ramón Castillo, un obrador de cooperativas creado en 2013 para establecer un contacto directo entre el intendente y los barrios (Bernal, 19/5/2014). 
tos espacios, la denominación de su espacio produjo malentendidos. Como ya indicamos anteriormente, Abriendo Rejas, refiere a una situación de violencia en la que ella se sentía presa y que cuando culmina le hace experimentar un sentimiento de liberación "milagrosa". Sin embargo, esta nominación se prestó a malentendidos para el sentido común jurídico predominante en el campo de derechos humanos en el cual querían insertarse:

"cuando nosotros ya creciendo nos metimos con CPM y el Comité Contra la Tortura, (...) algunos no entendían el concepto (...) nos decían 'bueno Abriendo rejas quiere decir que ustedes sacan a los presos, les abren las rejas a los presos'. Ahí surgió la necesidad de cambiar, como ya nos metimos en derechos humanos... algunos decían 'ah, son los que sacan a los presos por la puerta giratoria"' (Entrevista a Blanca Careaga, 18/2/19)

Aquí no solo vemos los motivos del cambio, sino que se refuerza un elemento señalado con anterioridad: la no vinculación con los sectores fundacionales de los movimientos de derechos humanos del país. Si consideramos que desde el año 2000, Careaga participó de espacios de extensionismo y asesoría, lo paradójico es que para ella fue solo al vincularse a una organización como la CPM, que consideró que efectivamente estaba operando "bajo la órbita de los derechos humanos".

Ante este escenario, el cambio de denominación de la agrupación se volvió una necesidad, cuando menos para evitar las críticas abiertas e infundadas que desde el campo se emitían sobre su organización. Esto ocurrió en 2007 y se decidió de manera conjunta entre los miembros de la organización. Lázaro levántate y anda:

"surgió por lo bíblico, el mismo pibe caído golpeado, torturado se tiene que levantar y también los familiares (...) el pibe, como que esta torturado por el mismo sistema, el Estado no le deja, es un pibe desclasado ¿no? pero nosotros tenemos que ponerle como un espejo. Lázaro levántate y anda es simbólico, es como que el pibe tiene que levantarse. Como organización tenemos que darle mucha contención" (Entrevista a Blanca Careaga, 18/2/19) 
La red de familiares contra la tortura y otras violencias estatales (CPM): sangre y reencantamiento del activismo.

Ante los malentendidos que se generaron en el campo, desde LLyA la búsqueda de una posición legitima al interior del campo de los activismo en derechos humanos se optó por explicitar desde el nombre el componente religioso entablando un puente entre la vivencia personal "milagrosa" que dio nacimiento a la organización y el horizonte del activismo buscado.

Aunque la apelación al imaginario religioso contrasta con el vocabulario secularizado más extendido de los derechos humanos, hace eco en extendidas formas de vinculación con lo sagrado que atraviesan a los distintos sectores sociales (Fidanza y Suárez, 2016) y en la trama religiosa que desde la constitución del campo está presente, como vimos, como forma de legitimación y de capital militante reconvertido. La novedad reside en el proceso de reencantamiento del activismo que busca impulsar.

\section{CONCLUSIONES}

A través de un recorrido, que comienza por la Comisión Provincial por la Memoria y sus integrantes, se pudo recuperar los antecedentes y reconstruir el surgimiento de la Red de Familiares contra la Tortura y Otras Violencias Estatales.

$\mathrm{Al}$ interior de este espacio nos encontramos con una experiencia particular de activismo, una organización de derechos humanos que explicita una discursividad religiosa, al invocar la figura del "milagro", en un campo como los derechos humanos históricamente distanciado del discurso religioso y reconocido socialmente por sus principios seculares.

El análisis desarrollado nos permitió realizar distintos aportes al campo del activismo de las víctimas. Por un lado, mostrar las continuidades entre activismo de distintas épocas, a partir del análisis de la hibridación entre activismos asociados a la última dictadura y al actual periodo democrático. Por el otro, analizar las disrupciones y emergencias, principalmente en torno a los significados atribuidos a la sangre y al dolor en la retórica de las organizaciones de familiares de una y otra época histórica. Por último, el análisis de rol de lo religioso en la trama activista nos permitió mostrar un in crescendo desde el papel acotado de la legitimación a la trabajo de reencantamiento de los derechos humanos. 
En lo que respecta a la sangre, los actores nos permitieron observar que los lazos familiares y un linaje que corre por las venas no son las únicas maneras en que ésta cobra sentido en el ámbito del activismo. Si bien las relaciones filiales continúan vigentes, coexisten con la "sangre de los derechos humanos", una sangre anónima que se presenta como una nueva variante para motorizar la lucha por derechos.

Respecto al reencantamiento del activismo en derechos humanos, la experiencia de la organización encabezada por Careaga permitió observar como un la narrativa religiosa como la del "milagro" se inserta de dos maneras en la esfera del activismo: posibilitandoló y reencantandoló. En primer lugar, por un "milagro" Careaga pudo mantener su vida y la "consagra al servicio de otros", creando una organización de familiares de víctimas. En segundo lugar, la explicitación de lo religioso en la denominación misma de la organización busca dar un salto y reencantar el campo de los derechos humanos. Por último, el recorrido realizado nos permitió mostrar la presencia de un imaginario religioso que circula, más allá de esta organización concreta, entre los miembros y las diversas organizaciones de la RED. Ahondar en dichas consideraciones excede el presente trabajo, aunque nos invita a profundizar nuestras indagaciones y a replantearnos el papel que la religión tiene al interior de un activismo de derechos humanos a priori concebido como secularizado.

\section{REFERENCIAS}

AGUDELO RAMÍREZ, M. El problema de la fundamentación filosófica de los derechos humanos: bases ontológicas. Tesis (Doctorado en Filosofía). Universidad de Salamanca, España, 2011.

ARNOSO MARTÍNEZ, M., BOMBELLI, J. I., MURATORI, M., MELE, S. V., y ZUBIETA, E. M. (2013). La CONADEP y el Informe Nunca Más: conocimiento, eficacia y emociones asociadas. Universidad de Buenos Aires. Facultad de Psicología. Secretaría de Investigaciones; Anuario de Investigaciones; Vol. 20, nº 1, pp. 197-205, 2013.

ARIAS, M. F. Liderazgo carismático y el ascenso de Menem a la Presidencia de la Nación en 1989. Colección, n³, pp. 31-35, 1996.

ARIAS, C., FONSECA, S. y García ALLEGRONE, V. Desindustrialización 
La red de familiares contra la tortura y otras violencias estatales (CPM):

sangre y reencantamiento del activismo.

y fábricas recuperadas. Una aproximación desde una perspectiva macroeconómica. In: VI Jornadas de Sociología. Facultad de Ciencias Sociales, Universidad de Buenos Aires, Buenos Aires, 2004.

BARROS, M. M., y MORALES, M. V. Derechos humanos y postkirchnerismo: resonancias de una década y esbozo de un nuevo panorama político. Universidad Nacional de Cuyo. Facultad de Filosofía y Letras; Estudios Sociales Contemporáneos; Vol.14; nº7, pp.104-124, 2016.

BERNAL, E. Rafael Castillo: "El hacer más cosas en los barrios, está en la agenda del intendente". Diario NCO. 19 de mayo de 2014. In: https://diario-nco.com/la-matanza/rafael-castillo-el-hacer-mascosas-en-los-barrios-esta-en-la-agenda-del-intendente/, accedido en 15 feb.2019.

BONVILLANI, A. Emocionalidad y espacio público: detenciones arbitrarias de jóvenes de sectores populares de Córdoba (Argentina). Cuaderno urbano. Espacio, cultura, sociedad, Vol.23, n²3, pp.107-124, 2017.

COMISIÓN NACIONAL SOBRE LA DESAPARICIÓN DE PERSONAS [CONADEP]. Nunca Más. Informe de la Comisión Nacional sobre la Desaparición de Personas. Buenos Aires: EUDEBA, 1984.

COMISIÓN PROVINCIAL POR LA MEMORIA [CPM, 2006]. Ojos que no ven. El sistema de la crueldad II. Informe sobre violaciones a los derechos humanos por las fuerzas de seguridad de la provincia de Buenos Aires 2005-2006. La Plata. In:http://www. comisionporlamemoria.org/static/prensa/cct/informesanuales/ Informe_2006.pdf, accedido en 21 feb.2019.

. [CPM, 2018]. El sistema de la crueldad XII. Sobre lugares de encierro, políticas de seguridad y niñez en la provincia de Buenos Aires, 2018. In:http://www.comisionporlamemoria.org/archivos/cct/ informesanuales/Informe_2018.pdf, accedido en 28 ene. 2019.

CAMPOS, E. ¿Que 20 años no es nada?: Globalización, posmodernidad $y$ rebelión en Argentina, de Menem a Kirchner (1988-2008). Argumentos, México, Vol.22, nº61, pp.95-123, 2009.

CATOGgio, M. S. The Consecration of Political Suffering: Martyrs, heroes and victims in Argentine Political Culture. Journal of Latin American Studies. Cambridge University Press, Londres. Vol.45, no04, pp. 695-719, 2013.

. Activismos no violentos bajo dictaduras militares en Argentina y Chile: el Servicio de Paz y Justicia, 1974-1983. Böhlau; Jahrbuch 
für Geschichte Lateinamerikas-Anuario de Historia de América Latina. Vol.52; nº12, pp. 291-315, 2015.

. Los desaparecidos de la iglesia: el clero contestatario frente a la dictadura. Buenos Aires: Siglo Veintiuno Editores, 2016a.

. Política contra el Estado autoritario, religión y derechos humanos. La impronta regional de un activismo trasnacional. Papeles de trabajo: La revista electrónica del IDAES, Vol.10, nº17, pp.182-206, 2016b.

CERRUTI, P. Genealogía del victimismo. Buenos Aires: UNQ, 2015.

COSACOV, N., PERELMAN, M., RAMOS, J., y RODRÍGUEZ, M. F. De "la Quema" al parque: notas sobre las políticas urbanas en la dictadura y la producción de pequeños consensos cotidianos en la Ciudad de Buenos Aires (1976-1983). Sociohistórica, Vol.29, pp.71$85,2012$.

COSTILLA, J. Itinerarios antropológicos para una etnohistoria comparada de la religión: cultos católicos americanos en la larga duración. Diálogo andino, n49, pp.299-309, 2016.

CRENZEL, E. Los derechos humanos, una verdad evidente de la democracia en la Argentina. Estudios-Centro de Estudios Avanzados. Universidad Nacional de Córdoba, Vol.29, pp.73-91, 2013.

CUENCA, A., y TRINCHERI, M. ¿Sin lucha no hay justicia? Concepciones de justicia en organizaciones de familiares de víctimas de violencia institucional. In: VI Jornadas de Sociología de la UNLP, Facultad de Humanidades y Ciencias de la Educación, La Plata, Argentina, 2010.

CUETO RÙA, S. Hijos de víctimas del terrorismo de Estado. Justicia, identidad y memoria en el movimiento de derechos humanos en Argentina, 1995-2008. Historia crítica, Vol.40, pp.122-145, 2010.

- Ampliar el círculo de los que recuerdan: La inscripción de la Comisión Provincial por la Memoria en el campo de los derechos humanos y la memoria [1999-2009]. Tesis (Doctorado en Ciencias de la Educación). La Plata: Universidad Nacional de La Plata. 2018.

. Criterios de selección de trabajadores en una institución estatal. Tensiones entre la agrupación HIJOS y la Comisión Provincial por la Memoria, Provincia de Buenos Aires. Clepsidra, Revista Interdisciplinaria de Estudios sobre Memoria, Vol.6, nº12, pp 128145, 2019. 
La red de familiares contra la tortura y otras violencias estatales (CPM):

sangre y reencantamiento del activismo.

DAWYD, D. M. M., MANCINI, Y., MEDINA, G., PANTANETTI, C. D., y DÍAZ HLAVKA, J. P. La militancia fabril en la zona oeste del Gran Buenos Aires y su lugar en las experiencias nacionales de radicalización, reorganización y represión sindical, 1966-1983. Estudio de caso de dos grandes fábricas siderúrgicas, "Santa Rosa"-(La Matanza) y "La Cantábrica" (Morón). Universidad Nacional de La Matanza, 2014.

DONATELLO, L. El catolicismo y la resistencia al neoliberalismo en la Argentina de la década de los 90": ¿nuevos sujetos colectivos? Informe final del concurso: Fragmentación social y crisis política e institucional en América Latina y el Caribe. Programa Regional de Becas CLACSO, 2002.

FIDANZA, J. M. L., y SÚAREZ, A. L. Diversidad de creencias, devociones y prácticas religiosas en los asentamientos precarios de la Ciudad de Buenos Aires. Religião \& Sociedade, Vol.36, nº1, pp.103-127, 2016.

GATTI, G. El misterioso encanto de las víctimas. Revista de estudios sociales, Vol.56, pp.117-120, 2016.

GAYOL, G., Y KESSLER, S. Muertes que importan. Buenos Aires: Siglo XXI, 2018.

GUGLIELMUCCI, A. La consagración de la memoria: Una etnografía acerca de la institucionalización del recuerdo sobre los crímenes del terrorismo de Estado en la Argentina. Buenos Aires: Antropofagia, 2013.

HERZER, H., DI VIRGLIO, M. M., GUEVARA, T., RAMOS, J., VITALE, P., e IMORI, M. Unos llegan y otros se van: cambios y permanencias en el barrio de La Boca. Población de Buenos Aires, Vol.8, n¹4, pp.7-27, 2011.

IZQUIERDO, G. M. Informantes y muestreo en investigación cualitativa. Investigaciones Andina, Vol.17, n³0, pp.1148-1150, 2015.

JELIN, E. Victimas, familiares o ciudadano/as: Las luchas por la legitimidad de la palabra., In: II Congreso Internacional de Filosofía de la Historia Reescrituras de la memoria social. Facultad de Filosofía y Letras, Universidad de Buenos Aires, 2006.

LAG, N. Un gatillo fácil cada 22 horas. Página/12. 3 de enero de 2019. In:https://www.pagina12.com.ar/165859-un-gatillo-facil-cada-22horas, accedido en 7 ene.2019.

LARRAlDE ARMAS, F. Políticas de la memoria. A propósito de su 
vigésimo aniversario en la ciudad de La Plata (Argentina): la configuración de un campo y sus prácticas. Revista mexicana de ciencias políticas y sociales, Vol.59, n²21, pp.267-289, 2014.

LASSO, R. F. Construcción de liderazgo y actitud mítica en presidentes constitucionales argentinos reelegidos. In: XV-Jornadas de Investigación y Cuarto Encuentro de Investigadores en Psicología del Mercosur, 2008.

LATINI, S. H. Primeros contactos e interacción en las costas del Plata a principios del siglo XVI. Relaciones de la Sociedad Argentina de Antropología, n³6, pp.345-351, 2011.

LENCI, L. y RAGGIO, M. S. Comisión Provincial por la Memoria, presentación de Actividades. Aletheia. Vol., 2, n³., pp. 1-20, 2011.

LORENZ, F. G. Archivos de la represión y memoria en la República Argentina. In: PÉROTIN-DUMON, A. (Dir.). Historizar el pasado vivo en América Latina, publicación electrónica, 2007. Disponible

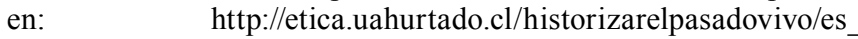
contenido.php accedido en 21 ene. 2019

MALLIMACI, F. Atlas de las creencias religiosas en la Argentina, Buenos Aires: Biblos, 2013.

MANZANO, V. De la matanza obrera a capital nacional del piquete: etnografía de procesos políticos y cotidianos en contextos de transformación social.-Tesis (Licenciatura en Ciencias Antropológicas). Facultad de Filosofía y Letras, UBA, Buenos Aires, Argentina, 2007.

MEJÍA, S. Wittgenstein y la creencia religiosa. Ideas y valores, Vol.55, $n^{\circ} 132$, pp.3-29, 2006.

OBSERVATORIO DE LA DEUDA SOCIAL ARGENTINAUNIVERSIDAD CATÓLICA ARGENTINA [ODSA-UCA, 2018]. Estancamiento Estructural, Pobrezas Crónicas, Exclusiones Económicas y Desigualdades Sociales en la Argentina (2010-2018), 2018. Disponible en: :http://uca.edu.ar/es/noticias/estancamientoestructural--pobrezas-cronicas--exclusiones-economicas-ydesigualdades-sociales-en-la-argentina-urbana--2010-2018-, accedido en 3 mar.2019.

PERELMAN, M., y TUFRÓ, M. Violencia institucional. Tensiones actuales de una categoría política central, 2016. Disponible en: http://www. sociales.uba.ar/wpcontent/blogs.dir/219/files/2016/11/04.-dossierPERELMAN.pdf, accedido en 24 feb.2019.

PITA, M. V. Familiares de victimas de la violencia policial. Demandas 
La red de familiares contra la tortura y otras violencias estatales (CPM):

sangre y reencantamiento del activismo.

de justicia y sensibilidades legales. Instituto de Ciencias Antropológicas. Facultad de Filosofía y Letras. UBA, Vol.24, nº7, p.6, 1997.

- Violencia policial y demandas de justicia: acerca de la forma de intervención de los familiares de víctimas en el espacio público. In: TISCORNIA,-S. (Comp.) Burocracias y violencia. Estudios de Antropología Jurídica. Buenos Aires: Antropofagía, pp.417-446, 2004

- Mundos morales divergentes: Los sentidos de la categoría de familiar en las demandas de justicia ante casos de violencia policial. In: III Jornadas de Investigación en Antropología Social. Facultad de Filosofía y Letras, Universidad de Buenos Aires, 2005.

. Formas de morir y formas de vivir: el activismo contra la violencia policial. Buenos Aires: Editores del Puerto, 2010.

POLLAK, M. Memoria, olvido, silencio. Estudos Históricos. Rio de Janeiro, Vol.2, n⿳3 3, pp.3-15, trad. Renata Olveira, 2006.

POMÉS, R. El municipio de La Matanza: desindustrialización y fragmentación social (1976-2003), s.f.

PEREYRA IRAOLA, V., y ZENOBI, D. Familiares de detenidos y abogados de derechos humanos: Trayectorias en la construcción de una causa pública. Runa, Vol.37, n², pp. 25-40, 2016.

RAGGIO, S. La enseñanza del pasado reciente. Clio \& asociados. La historia enseñada, Vol.8, pp.123-133, 2004.

- Jóvenes construyendo colectivamente la memoria. Revista Novedades Educativas, Vol.18, nº188, 2006.

- y CIPRIANO GARCÍA, R. La Comisión Provincial por la Memoria. Reflexiones en torno a la relación pasado presente en una experiencia temprana de institucionalización de las politicas de memoria en la Argentina. Clepsidra, Revista Interdisciplinaria de Estudios sobre Memoria, Vol.6, nº12, pp.108-127, 2019.

REBOLLAR, A. I. Una obra escultórica incluye víctimas de campos sociales excluyentes. El caso de la Masacre de Floresta, Buenos Aires (Argentina).- Papeles del CEIC, International Journal on Collective Identity Research, nº 1, p.1-28, 2017.

RED DE FAMILIARES. Comisión Provincial por la Memoria. S.f. Disponible en: http://www.comisionporlamemoria.org/project/redde-familiares/, accedido en 12 mar.2019.

RODRÍGUEZ ALZUETA, E. Circuitos carcelarios: el 
encarcelamiento masivo-selectivo, preventivo y rotativo en la Argentina. Question, Vol.1, 2012.

RODRÍGUEZ ALZUETA, E. Temor y control: la gestión de la inseguridad como forma de gobierno. Buenos Aires: Futuro Anterior, 2014.

SERRA, D. G., DURÁN, L., y PENELLA, C. Análisis del proceso de industrialización del Partido de La Matanza en el contexto local y nacional para el período 1930-2005. Ingenium, $\mathrm{n}^{\circ} 2$, pp.22-29, 2015.

SVETLITZA DE NEMIROVSKY, A. Tendencias en la dinámica de la estructura social agraria del partido de La Matanza,-1900-2000. Documento de Trabajo N 88, Universidad de Belgrano, 2002.

THOMASZ, A. G. Los nuevos distritos creativos de la Ciudad de Buenos Aires: la conversión del barrio de La Boca en el" Distrito de las Artes". EURE (Santiago), Vol.42, nº126, pp.123-144, 2016.

TISCORNIA, S. Violencia policial. De las prácticas rutinarias a los hechos extraordinarios. In: IZAGUIRRE, I. (Comp.), Violencia social y derechos humanos. Buenos Aires: Eudeba, pp.125-145, 1998.

VECCHIOLI, V. La nación como familia. Metáforas politicas en el movimiento argentino por los derechos humanos. In: FREDERIC, S. y SOPRANO,-G. (Comp.) Cultura y política en etnografías sobre la Argentina. Buenos Aires: UNQ/Prometeo, pp.241-270, 2005.

. Deserving victimhood: kinship, emotions and morality in contemporary politics. Vibrant: Virtual Brazilian Anthropology, Vol.15, nº3, 2018.

y LEAL, E. M. El activismo de las víctimas en contextos represivos y democráticos. Lecturas cruzadas. Papeles del CEIC, International Journal on Collective Identity Research, $n^{\circ} 1$, pp.1-11, 2017.

WOODS, M. Modalidades y límites de la intervención de la Iglesia Católica en conflictos sociales territoriales.-De la mediación a la confrontación en la diócesis de Quilmes. In: CRAVINO, C. (Ed.) Resistiendo en los barrios. Acción colectiva y movimientos sociales en el Área Metropolitana de Buenos Aires. Los Polvorines: Universidad Nacional de General Sarmiento, pp.77-99, 2007.

ZENOBI, D. S. Los familiares de víctimas de Cromañón, en la encrucijada del" dolor": Emociones, relaciones sociales y contextos locales. Universidade Federal da Paraíba. Grupo de Estudo e Pesquisa em Sociologia da Emoção; Revista Brasileira de Sociologia da Emoção, Vol.9, n²6, pp. 581-627, 2010.

ZENOBI, D., PÉREZ, M., GALARZA, A., CASTRO, M. L., MANSILLA, 
M., MOREIRA, F., BARRIOS, E., VANACOR, D., LUJÁN, C. y LUQUE WICKHAM, M. G.-Familiares-de-"presos comunes"-yexpertos-del-derecho: Primeros acercamientos a un proceso de organización y demanda. In: III-Jornadas de Debate y Actualización en Temas de Antropología Jurídica. PIP-CONICET-00560, Sección Argentina de la Red Latinoamericana de Antropología Jurídica (RELAJU) e I, San Martín, Prov. Buenos Aires, 2014.

ZENOBI, D., PÉREZ M, LOMBRAÑA A, LASTIRI D. y LIENDRO, M. 'Todo preso es...' Familiares de 'presos comunes' en el Encuentro nacional contra la violencia institucional” In: GARBI, S. y SODINI, D. (Coord.). Seguridad Pública, Violencias y Sistema Penal. Temperley: Tren en movimiento, pp.189-202, 2015. 
VARIA 